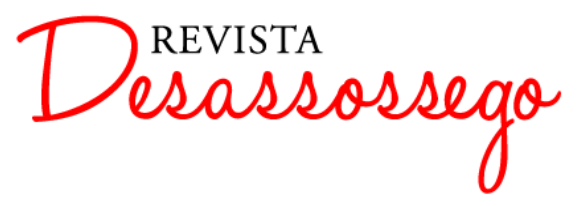

DESASSOSSEGO 15 | JUN/2016 | ISSN 2175-3180

DOI: http://dx.doi.org/10.11606/issn.2175-3180.v8i15p66-71

\title{
MENSAGEM, DE PESSOA: UMA EPOPEIA DA MODERNIDADE
}

\author{
José Clécio Quesado ${ }^{1}$
}

Recebido: 24/10/2015

Aprovado: 28/03/2016

\begin{abstract}
Resumo: O presente trabalho objetiva mostrar a Mensagem, de Fernando Pessoa, como manifestação do Modelo Épico Moderno que parte do vazio histórico do sonhado Quinto Império para o seu preenchimento com o mito do Encoberto. Para tanto, observa a sua articulação da temática da alteridade transcendente a partir de algumas ocorrências semânticas como naus, mares e o pronome outro, com suas consequentes proposições messiânicas. Na série literária, observa-se a articulação dialogal com o Modelo Épico Renascentista d'Os lusíadas, de Camões.
\end{abstract}

Palavras-chave: Literatura Portuguesa; Fernando Pessoa; Mensagem; Epopeia; Modernidade.

\section{MENSAGEM, BY PESSOA: A MODERN EPIC}

\begin{abstract}
This article aims at presenting Fernando Pessoa's Message (Mensagem) as a manifestation of the Modern Epic Model which starts from the historic void of the longed-for Fifth Empire and fills it with the myth of The Hidden One (O Encoberto). In order to do so, the paper looks into the way the transcendent alterity theme is articulated with its consequent messianic propositions by means of the occurrence of semantic forms like naus (ships), mares (seas) and the pronoun outro (other). Taking the literary sequence into consideration, the article reveals the poem's dialogical articulation with the Renaissance Epic Model of The Lusiads (Os lusiadas) by Camões.
\end{abstract}

Keywords: Portuguese Literature; Fernando Pessoa; Message; Epic; Modernity.

'Screvo meu livro à beira-mágoa. Meu coração não tem que ter.

Como elaboração estética dentro do processo literário, o discurso épico é único desde o seu primeiro registro na história ocidental com Homero, sistematizado por Aristóteles, até os tempos atuais. O que difere, contudo, é a sua forma de manifestação que é modulada pela imagem de mundo construída no momento em que ela se produz e pela articulação do seu

\footnotetext{
${ }^{1}$ Professor Associado da Universidade Federal do Rio de Janeiro.
} 


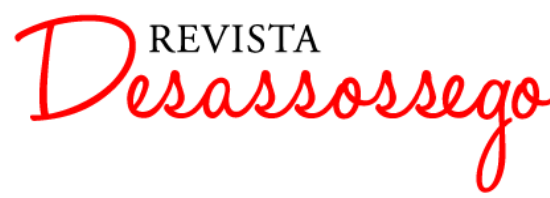

DESASSOSSEGO 15 | JUN/2016 | ISSN 2175-3180

DOI: http://dx.doi.org/10.11606/issn.2175-3180.v8i15p66-71

sujeito enunciador. A sua forma de manifestação discursiva é também um elemento modelar. $\mathrm{Na}$ Antiguidade, quando os deuses ou semideuses eram evocados para consubstanciar essa imagem de mundo e o lugar da existência do homem nele situado, é de se entender que o herói divino fosse eleito para dimensionar o sentido de realidade. Essa é a formulação do Modelo Épico Clássico com exemplos em Homero e Virgílio. No contexto antropocêntrico do Renascimento, o homem real, sujeito de sua história, obviamente passa a ser o herói histórico a caminho da divinização, como é o caso de Vasco da Gama n'Os lusíadas que, no seu caminho de agruras pelo mar, alcança a Ilha dos Amores. Essa é a formulação do Modelo épico Renascentista que, resgatando o clássico, supera-o e o transforma. Na modernidade, contudo, perdida a imagem de mundo e também a integralidade do indivíduo que a possa sustentar, resta a concepção fragmentária do sujeito e a consciência do vazio do real. Vem daí que a manifestação épica, mesmo sendo por sua própria índole discursiva o produto de um resgate da história dos deuses ou dos homens e, ainda, do próprio discurso que a precede, tem de partir do vazio, ou seja, da descontinuidade e da fragmentação. É este o posicionamento epistemológico do Modelo Épico Moderno e, se formos mais longe ainda, de modo mais radical, do pós-moderno.

Para os de "Orpheu", já não havia mais uma realidade histórica sustentável desde a consciência crítica genialmente expressa pela poesia secamente prosaica de um Cesário Verde ou da visão vagamente saudosista da poética já dispersa de um Antônio Nobre.

Assim é a Mensagem, de Fernando Pessoa: uma epopeia que, tanto na série históricosocial quanto na literária, parte do arquétipo vazio do mito do Quinto Império e da falência do próprio discurso épico precedente, na busca de supri-los com uma nova dicção de feição tãosomente messiânica e subjetivadora. E por isso ela se enquadra no rol das utopias regressivas. Tomando, pois, como ponto de partida a consciência do fim da história e dos limites do sentido do discurso que a fala, esse poema pessoano se propõe o resgate desses discursos -- o histórico e o literário -- buscando construir os não-limites de uma outra dimensão: a dimensão transcendente.

Mensagem também é uma epopeia de viagem e, nesse ponto, a princípio, em nada se distancia daquilo que é uma das propriedades básicas dessa manifestação discursiva. Igualmente à Odisseia e a'Os lusíadas, o espaço de sua referenciação é principalmente o mar, e o 


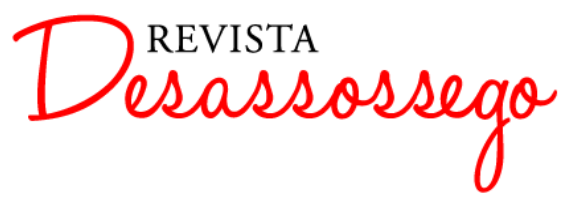

DESASSOSSEGO 15 | JUN/2016 | ISSN 2175-3180

DOI: http://dx.doi.org/10.11606/issn.2175-3180.v8i15p66-71

instrumento de navegação é a nau. Não se trata, porém, de uma navegação dimensionada no plano da realidade mítica antiga ou histórico-renascentista, mas de uma trajetória extraída dele e projetada numa dimensão transcendente, já que o seu ponto de partida é justamente o fim da história do Império dos mares. Não é por acaso que nau e mar se fazem presentes como verdadeiros metassemas ao longo de todo esse poema de poemas, como que a estruturar seu arcabouço de sentido. É prova disso o fato de esses dois termos estarem presentes nas três partes que o compõem (Brasão, Mar português e O Encoberto). E os termos nau e mar aparecem referenciados de modo direto em 18 dos seus 44 breves poemas, num total de mais de meia centena de ocorrências. Naus e mares aparecem desde as "naus a haver" do poema "D. Dinis", sexto castelo do Brasão, primeira parte da Mensagem, até o "fim do mar" de "Antemanhã", penúltimo de todos eles. E são mais que naus concretas de um "oceano por achar". Na Mensagem busca-se, essencialmente, o resgate mítico da "última nau” (penúltimo poema de Mar português) no "mar da idade" ("Noite"), isto é, na utopia do Encoberto a desvelar-se na transcendência de uma Distância "Do mar ou outra, mas que seja nossa!" ("Prece”). Esta “outra Distância”, miticamente marcada pela maiúscula alegorizante, é precisamente o objeto da busca transcendente, configurando, assim, uma proposta de alteridade que se projeta a partir da História, sim, mas para além dela.

Numa elaboração estética magistralmente construída como é o caso dessa obra-prima de Pessoa e de todas as literaturas de língua portuguesa, a totalidade de seu sentido se encontra, por vezes, identificável até mesmo através de certas particularidades que, sob a forma de ícones, estruturam sua significação. Assim, se perseguirmos as demais ocorrências desse pronome indefinido outro nesta mesma acepção de alteridade transcendente, perceberemos que, como naus e mares, elas também pontilham todo o texto da Mensagem. Sua primeira incidência acontece logo no poema de "D. Tareja", o segundo dos castelos do Brasão. Essa princesa castelhana, juntamente com o conde D. Henrique, forma emblematicamente, na condição de pais do fundador do Reino, os pilares da história portuguesa. E esse pronome indefinido se faz aí presente na forma do primeiro dos apelos messiânicos que perpassam toda essa epopéia:

Dê tua prece outro destino

A quem fadou o instinto teu! 


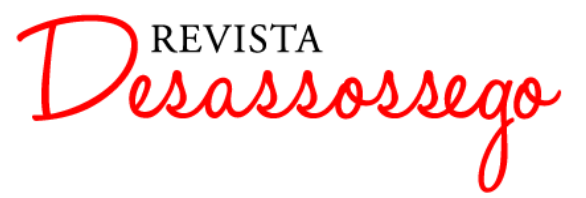

O homem que foi o teu menino

Envelheceu.

A alteridade do novo destino suplicado se dá a partir da constatação do envelhecimento daquele que foi o fundador do Reino, D. Afonso Henriques, isto é, a partir do fim da história do próprio império. Esse “outro destino” é o objeto nodal do sonho messiânico da Mensagem.

Uma nova ocorrência do termo aparece no poema que simboliza a quinta e última quina do Brasão, primeira parte desse livro-poema, em cujo texto fala aquele que, para o enunciador da Mensagem, é o verdadeiro sujeito da história portuguesa: D. Sebastião. Nessa dicção confessional de autoassunção do delírio transcendente, o rei, cuja morte prematura aos 24 anos consumou também o fim do sonho imperial, apela para que outros retomem a sua "loucura". Não ela só, mas principalmente, "o que nela ia", ou seja, a unção metafísica do querer "grandeza qual a sorte a não dá", porque o sonho transpõe os limites do sentido de se ser somente "a besta sadia, / Cadáver adiado que procria". E o texto se encerra messiânica e conceitualmente:

\footnotetext{
Com o que nela ia.

Sem a loucura que é o homem

Mais que a besta sadia,

Cadáver adiado que procria?
}

Minha loucura, outros que me a tomem

Mais adiante e já no poema "Prece", último de Mar português, segunda parte dessa epopeia pessoana, o sujeito enunciador, agora investido da condição coletiva de um nós, e consciente de que "Restam-nos hoje, no silêncio hostil, / O mar universal e a saudade", apela àquele mesmo senhor do fim da História para que ele seja o agente da transmutação espiritual dela:

Dá o sopro, a aragem -- ou desgraça ou ânsia --,

Com que a chama do esforço se remoça 


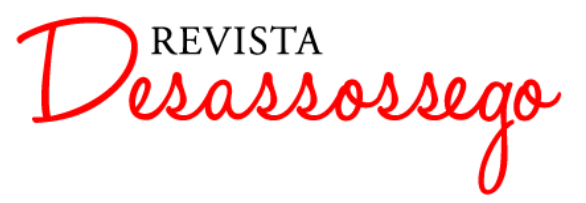

DESASSOSSEGO 15 | JUN/2016 | ISSN 2175-3180

DOI: http://dx.doi.org/10.11606/issn.2175-3180.v8i15p66-71

E outra vez conquistemos a Distância --

Do mar ou outra, mas que seja nossa!

Quase ao final d' O Encoberto, terceira e última parte da Mensagem, mais precisamente no poema "Calma", que medeia a passagem d' Os Tempos do caos dos poemas "Noite" e "Tormenta" para os da epifania dos poemas finais "Antemanhã" e Nevoeiro", surge a derradeira marcação semântica dessa opção por uma alteridade transcendente. E tudo ocorre na forma de uma angustiada e duvidosa espera por um espaço utópico em que o Rei, já agora mais idealizado, possa exercer o seu domínio espiritual:

\author{
Haverá rasgões no espaço \\ Que dêem para outro lado, \\ E que, um deles encontrado, \\ Aqui, onde há só sargaço, \\ Surja uma ilha velada, \\ O país afortunado \\ Que guarda o Rei desterrado \\ Em sua vida encantada?
}

Essa busca por uma alteridade transcendente que esteja para além dos limites do sentido real se dá, pois, a partir de uma melancólica consciência do fim da História, e apresenta para com ela uma articulação veladamente dialética e expressamente elegíaca. É o que constitui a significação na série social da Mensagem, de Fernando Pessoa, que dialoga com a história do império do ultramar, sabendo-a finda e a evocando sob a forma de um verdadeiro réquiem.

$\mathrm{Na}$ série literária, igualmente ocorre na Mensagem um diálogo velado e de certa inversão modelar para com Os lusíadas, de Camões, e toda a tradição épica. Não se trata de um resgate intertextual senão no plano da enunciação. E pode-se mesmo dizer que a epopeia pessoana é uma negação, uma desrealização daquela do poeta renascentista, na sua forma de manifestação do Modelo Épico Moderno. E ainda é visível que Camões é, expressa e intencionalmente, o grande esquecido de Pessoa. Haja vista o fato de que em nenhum dos versos da Mensagem se 


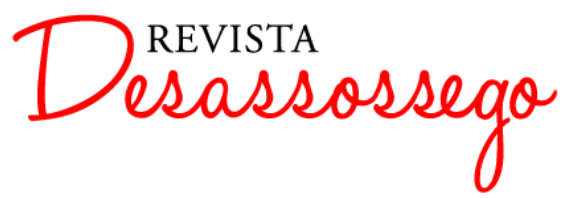

DESASSOSSEGO 15 | JUN/2016 | ISSN 2175-3180

DOI: http://dx.doi.org/10.11606/issn.2175-3180.v8i15p66-71

pode dizer que ecoam de modo explícito referências camonianas. E isso até seria o normal em se tratando de uma realização épica como é o caso que ocorre, por exemplo, com o próprio vate renascentista em relação a Virgílio. Camões não se encontra, como era de se esperar, entre os Avisos d' O Encoberto, por mais que ele tenha visto D. Sebastião, o rei do seu momento histórico, como a "Maravilha fatal da nossa idade, / Dada ao Mundo por Deus, que todo o mande, / Para do mundo a Deus dar parte grande". Dois dos avisos são: um o Bandarra, que antecede no tempo a D. Sebastião, e outro Antônio Vieira que o sucede. O terceiro é o próprio sujeito enunciador que, de instância lírico-narrativa, passa a ser o próprio sujeito autoral do seu "livro à beira-mágoa". É o próprio Fernando Pessoa. E nisso consiste mais um caráter de modernidade dessa epopeia pessoana, qual seja, a dominância da instância lírica sobre um discurso que é, apenas fragmentária e descontinuamente, uma narrativa. Com efeito, essa instância enunciadora se apresenta explicitamente em 17 dos 44 poemas, numa atmosfera de absoluta subjetivação. Isso se dá ora pela fala do personagem, ora sob a forma de agente articulador do mito de renovação como ocorre no poema "A última nau", até chegar ao minúsculo verso final, quando, tendo constatado que Portugal - hoje - é nevoeiro, evoca messianicamente que "É a Hora!".

\section{Bibliografia}

PESSOA, Fernando. Mensagem - Poemas esotéricos. Edição crítica. José Augusto Seabra

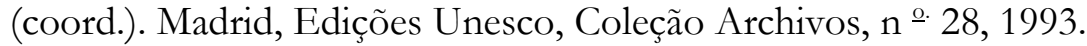

QUESADO, Clécio. Mensagem, de Pessoa: labirintos de um poema. Rio Bonito: Almádena. 2014.

SILVA, Anazildo Vasconcelos da. Semiotização literária do discurso. Rio de Janeiro: ELO, 1984. 